A N N A L E S Annales de Bretagne et des Pays de l'Ouest

Anjou. Maine. Poitou-Charente. Touraine

115-1 | 2008

Varia

\title{
Les écrits du for privé dans le Haut-Maine à l'époque moderne
}

\author{
Mathilde Chollet
}

\section{OpenEdition}

\section{Journals}

Édition électronique

URL : http://journals.openedition.org/abpo/360

DOI : 10.4000/abpo.360

ISBN : 978-2-7535-1509-3

ISSN : 2108-6443

Éditeur

Presses universitaires de Rennes

Édition imprimée

Date de publication : 30 mars 2008

Pagination : 133-158

ISBN : 978-2-7535-0653-4

ISSN : 0399-0826

\section{Référence électronique}

Mathilde Chollet, «Les écrits du for privé dans le Haut-Maine à l'époque moderne », Annales de

Bretagne et des Pays de l'Ouest [En ligne], 115-1 | 2008, mis en ligne le 30 mars 2010, consulté le 02 mai 2019. URL : http://journals.openedition.org/abpo/360 ; DOI : 10.4000/abpo.360 


\title{
Les écrits du for privé dans le Haut-Maine à l'époque moderne
}

\author{
Mathilde CHOLLET \\ Étudiante $^{1}$
}

Le terme de "for privé " apparaît pour la première fois sous la plume de Madeleine Foisil dans l'article "L'écriture du for privé ${ }^{2}$ ". Cette expression désigne une pratique culturelle privée et s'applique à l'ensemble des écrits où la prise de parole du rédacteur est " directe et sans intermédiaire ${ }^{3}$ ", textes écrits à la première personne, dans lesquels l'auteur laisse une trace de son vécu, de son quotidien et de ses opinions personnelles, quand il ne s'agit pas d'un document où plusieurs membres d'une même famille se succèdent pour tenir la plume. On parle aussi d'ego-documents, terme conçu aux Pays-Bas, ou d'écritures du $\mathrm{moi}^{4}$. Le travail actuel sur les écrits du for privé se fait en Italie, en Suisse, aux Pays-Bas et aussi en France, notamment à travers un recensement de ces écrits mené dans chaque département, à l'initiative de Jean-Pierre Bardet et François-Joseph Ruggiu dans le cadre du GDR n ${ }^{\circ} 2649$.

Pays de bocage à la coutume parfaitement égalitaire, le Haut-Maine travaille le chanvre, l'étamine, la cire, et produit des céréales, du vin et du cidre. Certaines de ces activités se retrouvent à travers deux exemples d'écrits du corpus empruntés au XvIII ${ }^{\mathrm{e}}$ siècle, à savoir les mémoires de l'étaminier Louis Simon ${ }^{5}$, mais aussi les ego-documents de la famille Le Prince ${ }^{6}$ qui a fait fortune dans le négoce des cires et bougies. Le corpus des ego-documents, ou écrits du for privé, du Haut-Maine constitué pour

1. Cet article est issu d'un mémoire de master 2 soutenu à l'université du Maine en juin 2006 sous la direction de Frédérique Pitou.

2. ARIÈs, Philippe et DuBY, Georges (dir.), Histoire de la vie privée, Paris, Seuil, 1999, tome 3 .

3. BARDET, Jean-Pierre et RugGiu, François-Joseph (dir.), Au plus près du secret des cœurs? Nouvelles lectures historiques des écrits du for privé en Europe du XVI au XVII ${ }^{e}$ siècle, PUPS, 2005, p. 7.

4. DeKKER, Robert, "Les égodocuments aux Pays-Bas du XVI ${ }^{\mathrm{e}}$ au XVIII ${ }^{\mathrm{e}}$ siècle ", Bulletin du Bibliophile, 1995, p. 317-332.

5. FILLON, Anne, Louis Simon, villageois de l'ancienne France, Rennes, Ouest-France, 1982.

6. Arch. dép. de la Sarthe, 1 Mi 4 R3. Livre de raison de la famille Bouteiller-Le Prince. 
cette étude se compose de trente-huit documents, tous rédigés durant une époque moderne élargie (1490-1865), par trente-trois auteurs, issus de trente familles différentes du Haut-Maine, à l'exception du diariste Stanislas Dupont de la Motte, originaire d'Arras mais habitant La Flèche. Leurs écrits couvrent parfaitement l'ensemble de la période moderne. On remarquera la diversité des auteurs : hommes et femmes, comme Henriette Edme des Rouaudières, diariste du XvIII ${ }^{\mathrm{e}}$ siècle qui commence le premier de ses trois journaux avant son mariage en $1755^{7}$; jeunes ou plus âgés, ils sont catholiques comme protestants, comme l'est la famille Le Gendre (1523-1662) ${ }^{8}$. Ils appartiennent au monde urbain : les familles Bodreau, Le Divin, Le Vayer, ou encore Bouteiller, font partie des grands noms de la ville du Mans; mais aussi aux campagnes du Haut-Maine; ainsi, Jacques Montereul, notaire à Saint-Georges-du-Bois, laisse un livre de raison pour les années 1534 à $1543^{9}$. Ces trente-trois auteurs représentent les trois ordres de la société. Charles de Chenevières, auteur d'un livre journal (1591-1622) ${ }^{10}$ mal conservé, est issu d'une famille noble de la province, tandis que François Ménard de la Groye appartient à une famille de magistrats de la vieille bourgeoisie mancelle. Des membres du clergé du Maine ont laissé des livres de raison, ainsi le curé de Saint-Léonard-des-Bois Louys Pousteau (ou Pasteau), entre 1649 et $1679^{11}$, ou bien des journaux, comme celui de René Nepveu de la Manouillère, chanoine de la cathédrale Saint-Julien du Mans, malgré le titre de Mémoires donné par l'éditeur scientifique, rédigé entre 1759 et $1807^{12}$. Toutefois, cette diversité est limitée car dans l'ensemble, ces auteurs appartiennent tous à l'élite sociale et culturelle, rurale comme urbaine, de la province.

Ce corpus est composé de huit livres de raison ou de comptes, huit livres de famille : c'est dans ces écrits, destinés à être poursuivis de père en fils, que les événements concernant plus ou moins directement la famille sont consignés; de cinq journaux (pas forcément intimes) ou diaires, tenus au jour le jour, de onze mémoires, écrits subjectifs écrits a posteriori, dont des chroniques et récits de voyage ou de prison, ainsi que de simples notes. Il regroupe les possessions des fonds publics de la Sarthe que sont les Archives départementales (séries $\mathrm{E}, \mathrm{F}, \mathrm{J}$ et microfilms) et la médiathèque municipale Louis Aragon du Mans. Aux documents conservés dans ces deux organismes d'archives publiques, s'ajoutent deux ego-documents publiés et que l'on peut consulter facilement; il s'agit du Journal de Dupont

7. Arch. dép. de la Sarthe, 1 Mi 3 R12. EdME DES RouAudiÈRES, Henriette, Mémorial à mon usage particulier (1752) ; Réflexions journalières (1753-1754); Confidences générales et particulières.

8. "Le livre de raison de la famille Le Gendre ", Revue Historique et Archéologique du Maine, t. XXIII, p. 114-154.

9. Arch. dép. de la Sarthe, 4 E 103/1.

10. Arch. dép. de la Sarthe, 7 J 33. Papier journal de Charles de Chenevières.

11. Arch. dép. de la Sarthe, 1 Mi 57 R1. Journal de Louys Pasteau.

12. Esnault, Gustave-René, Mémoires de René-Pierre Nepveu de la Manouillère, chanoine de l'église du Mans, Le Mans, Pellechat, 1877-1878, p. 268. 
de la Motte ${ }^{13}$ et des Mémoires de Louis Simon. Le corpus est largement constitué de copies : pour un tiers seulement les ego-documents étudiés ici sont des manuscrits originaux, en plus ou moins bon état de conservation. Les autres sont des copies manuscrites d'érudits des $\mathrm{XIX}^{\mathrm{e}}$ et $\mathrm{XX}^{\mathrm{e}}$ siècles, des microfilms de conservation, ou des publications dans des revues locales. Seul le récit de voyage du fléchois René Desboys du Chastelet a été publié de son vivant, en $1665^{14}$. L'écrit le plus ancien, le livre de famille de Charles Bourgouing ${ }^{15}$, commence en 1490, alors que le plus récent, le livre de raison de la famille Ménard de la Groye ${ }^{16}$, commencé par François Ménard de la Groye, se termine en 1865. Les mémoires sont plutôt caractéristiques du XVIII ${ }^{\mathrm{e}}$ siècle, les plus anciens du corpus étant ceux rédigés à la fin du XVII ${ }^{\mathrm{e}}$ par Du Guesclin rassemblant ses souvenirs à la fin de sa vie ${ }^{17}$. À l'inverse, le livre de raison apparaît, dans le Haut-Maine, comme un genre d'écrit privé majoritairement issu de la première modernité : sept sont commencés au cours du XVI ${ }^{\mathrm{e}}$ siècle. Les livres de raison conservés pour le XVIII ${ }^{\mathrm{e}}$ siècle sont ceux de Urbain Termeau (1705-1743) ${ }^{18}$ et de François Ménard de la Groye (1683-1865). Malgré cette annotation sur la deuxième de couverture, datée de 1683 : "Mr Claude René Ménard de la Tu, En 4 au collège du Mans le 29 août 1683 ", c'est bien François Ménard de la Groye qui est le premier à tenir véritablement le livre de raison de la famille, qui commence par ce sous-titre, "Epoques des evenemens les plus interessans par rapport à moi ». Les autres livres de raison ou de famille couvrant le XVIII ${ }^{\mathrm{e}}$ siècle ont été commencés au siècle précédent, comme par exemple celui de la famille Bouteiller (1669-1697), qui fut transmis ensuite à la famille Leprince (17371757) ${ }^{19}$, ou bien celui de René de Vanssay, qui s'inscrit dans une tradition familiale lorsqu'il tient son livre de raison ${ }^{20}$. Au final, le corpus des écrits du for privé du Haut-Maine pour la période moderne n'est pas très épais, mais son contenu se révèle dense.

Quels thèmes privilégie l'auteur écrivant en son for privé? La ville et la paroisse, d'abord : ce sont ici la ville du Mans et ses quartiers, et les différents villages du Haut-Maine que l'on retrouve dans les récits du corpus. Plus proches encore de l'auteur, le voisinage et la maison, fort représentés dans les écrits du for privé, appartiennent à la chronique familiale que sont le livre de raison, le journal ou même les mémoires. L'individu s'accorde-t-il toutefois une place privilégiée dans ses écrits?

13. Borsson, Didier, Le journal de Stanislas Dupont de la Motte, Rennes, PUR, 2005.

14. Desboys Du Chastelet, René, L'Odyssée, et diversité d'avantures, rencontres et voyages en Europe, Asie et Affrique, divisée en quatre parties, La Flèche, G. Laboe, 1665, 202 et 203 p. en un volume.

15. Médiathèque Louis Aragon, Le Mans, Ms B 533.

16. Arch. dép. de la Sarthe, $10 \mathrm{~J} 80$, Livre de raison de Ménard de la Groye.

17. Arch. dép. de la Sarthe, 7 F 92, Extraits des mémoires de Du Guesclin.

18. Arch. dép. de la Sarthe, 46 J 178, Livre de raison de la famille Termeau-Brard.

19. Arch. dép. de la Sarthe, 1 Mi 4 R3.

20. Arch. dép. de la Sarthe, 1 Mi 3 R59, Livre de raison de René de Vanssay. 


\section{Une chronique de l'ordinaire}

La nature de l'écrit du for privé le place dans un environnement majoritairement réduit à l'univers proche de son auteur. Ainsi, deux grands cadres de vie délimitent sa portée, essentiels pour les hommes de l'époque moderne; il s'agit, d'une part, de la province de l'auteur, et d'autre part, de la famille à laquelle il appartient. La quasi totalité de la vie se déroule pour tous à l'intérieur de ces deux ensembles, les voyages restent exceptionnels. L'importance de la ville du Mans et de la possession de la terre se dégage des récits de nos auteurs. Les différentes étapes de la vie au sein de la famille composent l'essentiel des récits de vie, journaux et livres de famille du corpus, qui tentent de mettre en valeur la famille à laquelle on appartient, dans l'optique de la transmission de la mémoire familiale.

\section{Vivre dans le Maine}

Les faits divers, curieux ou tragiques, intéressent plus les diaristes, toujours informés des événements survenus autour d'eux : les accidents naturels, "Le tonnerre a tué un jeune homme auprès de Verron ${ }^{21}$ ", chez l'inspecteur du collège de La Flèche Dupont de la Motte, la présence de " chiens enragés du côté de Créans ${ }^{22}$ " sont dignes d'être notés, et l'avocat Charles Bodreau marque lui aussi un siècle avant, vers Pâques 1673, l'arrivée de " bestes feroces l'on dit que sont loups serviers, leopards lions qui ont devoré et mordu plusieurs enfans autour de nostre ville du Mans ${ }^{23}$ ". La peur du loup est encore ancrée en Anjou, Maine et Touraine, où ces bêtes ont provoqué de grands ravages au cours des siècles précédents, " Dieu nous preserve de cet acident ", rajoute même Bodreau. On note aussi les accidents survenus dans les environs, par exemple dans le journal de l'inspecteur du collège de La Flèche, le naufrage d'un bac et plusieurs noyades dans la Sarthe à Malicorne : "Il était rempli de paysans de Noyen qui allaient à la messe dans le $1^{\text {er }}$ de ces endroits. De 75 personnes, on dit que 10 seulement se sont sauvées ${ }^{24}$ ", raconte-t-il. Le suicide d'une femme près de Cré-sur-Loir permet à Charles Boucher, chirurgien de La Flèche, de déplorer le manque de traitements médicaux dans les zones rurales reculées à la fin du XVIII ${ }^{\mathrm{e}}$ siècle : " Depuis quelque tems elle souffroit de violents maux de tête, puis sa raison avoit paru un peu s'alliéner. La médecine eut empesché ce suicide ${ }^{25}$ ", déplore-t-il dans les Ephémérides fléchoises.

Les exécutions par la justice locale attirent un public nombreux, et beaucoup, sans y assister, s'y intéressent. Vers la fin du règne de Louis XV, Henriette Edme des Rouaudières explique pourquoi un violeur finit sur le

21. Borsson, Didier, Le journal de Stanislas..., op. cit., p. 137. C'était le 7 juillet 1773.

22. Ibid., 30 avril 1774, p. 190.

23. Arch. dép. de la Sarthe, $1 \mathrm{~J} 364$; livre de raison de la famille Bodreau, $\mathrm{f}^{\circ} 254$

24. Boisson, Didier, Le journal de Stanislas..., op. cit., p. 172.31 janvier 1774.

25. Arch. dép. de la Sarthe, 13 F 1517. Boucher, Charles, Ephémérides fléchoises. 
bûcher : " On a fait brûler dans ce païs-cy un jeune homme qui s'amusoit à violer des jeunes filles et les étrangloit ensuitte ou les noyoit; comme il s'est trouvé coupable aussi de bestialité, cela luy a procuré le feu ${ }^{26}$. " Le sensationnel et les faits morbides alimentent les conversations, on trouve dans le journal de Dupont de la Motte un exemple d'arrestation tardive : " On vient d'arrêter ici un malheureux, qui a assassiné il y a 20 ans sa mâ̂tresse étant enceinte ${ }^{27}$. " Dans ces écrits, le lecteur découvre les villages du Haut-Maine à travers des cas de violence exceptionnels, mais aussi à travers des descriptions et des changements auxquels l'auteur assiste, et qui jalonnent la vie de province. Grâce aux notes prises par Julien II Bodreau, on suit le déroulement d'une exécution pour blasphème en 1662 : l'accusé porte sur lui un écriteau indiquant la raison de sa condamnation : "Il luy fut mis un papier ecrit au dos contenant Execrable blasfemateur du nom de Dieu ${ }^{28}$ "; avant de mourir, le blasphémateur doit encore faire amende honorable en public, devant une église, "nud en chemise une torche ardente en main au devant de la grande porte de l'eglise collegiale du Grand Sct Pierre "; il est ensuite conduit aux halles de la ville, où a lieu le supplice réservé aux blasphémateurs : "La langue coupée, et après pendu et etrangle et au bas de la potence estre son corps brusle et ses cendres jettees au vent. " On peut multiplier les exemples d'exécutions à mort publiques, relatées par les auteurs du corpus, et qui montrent l'importance de la vie sociale.

La vie d'une ville de province offre évidemment plus de variété que celle des campagnes, comme le montre l'exemple du Mans, capitale du HautMaine. Des nobles du Mans organisent et offrent un bal public à la ville le 23 janvier 1777, avant le Carême. Le chanoine Nepveu de la Manouillère raconte qu'ils « ont donné un bal dans la salle de spectacle à toute la ville, depuis quatre heures du soir jusqu'à onze heures ${ }^{29}$ ". " On a, cette année, la fureur de la danse; toutes les semaines, il y a un bal jusqu'au carnaval ${ }^{30}$ "; après le mercredi des Cendres, tout divertissement est interdit jusqu'à Pâques; si la période du carnaval ne voit plus de charivari, elle reste celle des divertissements avant le jeûne. La vie religieuse de la ville, siège d'un évêché, intéresse les auteurs du corpus, relatant les nouveautés au niveau des paroisses de la ville, et les intronisations des évêques; ces cérémonies étant longuement décrites par les auteurs du corpus, et l'on peut ainsi connaître la liste des évêques qui se sont succédé au cours des XVII et XVIII ${ }^{\mathrm{e}}$ siècles. En recoupant les ego-documents, on assiste à la succession des évêques du Mans pendant plus d'un siècle.

26. EDME DEs RouAudières, Henriette, Confidences générales... op. cit., p. 168.

27. BoIsson, Didier, Le journal de Stanislas..., p. 72 (4 mars 1772).

28. Arch. dép. de la Sarthe, $1 \mathrm{~J} 364$; livre de raison de la famille Bodreau, f ${ }^{\circ} 220 \mathrm{v}-221$.

29. Esnault, Gustave-René, Mémoires de René-Pierre Nepveu..., op. cit., p. 268.

30. Ibidem. 


\section{L'importance de la terre}

La terre, la fierté de la posséder, est un sujet traité par les propriétaires fonciers et les habitants des campagnes, à travers les descriptions et les comptes relatifs à leur domaine. Le livre du cultivateur Montaron, à la fin du $\mathrm{XVIII}^{\mathrm{e}}$ siècle, contient la description des arbres qui ont été plantés sur la terre du Sablonnier ou Sablonnay, chênes " gros comme la cuixe ${ }^{31}$ ", ormeaux, pommiers et poiriers. Plus loin, il fait la liste des " Arbre qui ont été abatu sur la taire du Sablonnier ${ }^{32}$ ». Dans son journal Guyot de l'Hommaie recense tous les ans ses champs cultivés et les revenus qu'il en attend. En 1699, on peut lire, pour un champ qu'il a oublié de nommer : " Jay cette année ensemencé le Champ du [blanc] il y a entre dix neuf boisseaux de bled, et la cave avec l'allée ou il a entre 29 boisseaux de semences. Cy 48 b. ${ }^{33}$. " Dans la même entrée, il continue la liste de ses ensemencements : « Jay fait trois journaux d'avenne d'hyver dans le haut du Gast en retour le milieu a esté ensemencé de meslot, et j'ay laissé le bas à orge ${ }^{34}$. " La principale utilisation que Guyot fait de son journal est de tenir les comptes des revenus provenant de ses terres, auxquelles il fait de nombreuses références. Nepveu de la Manouillère s'intéresse à la terre pour la culture de la vigne, c'est pourquoi il constate, en 1770 : «Depuis longtemps on n'avait vu d'aussi mauvaises vendanges, et il y a quatre ans que l'on a eu de bon vin ${ }^{35}$." En ce qui concerne René de Vanssay, de Conflans-sur-Anille, son autobiographie devient vite une énumération des achats et ventes de terres qu'il réalise, ce qui traduit l'importance qu'il y attache. En effet, lorsqu'en 1719 le Régent fait rembourser avec les billets de la banque Law les rentes dues par l'État, René de Vanssay s'empresse d'acheter des terres ${ }^{36}$. À la même époque, la terre d'Ardenay est le souci de ses deux propriétaires successifs, Jean-Baptiste Le Prince, puis son fils, Jean-Baptiste Le Prince d'Ardenay. Le mémorialiste dit l'importance de cette terre pour lui et son père : " J'étais vraiment attaché à raison de ses agréments et plus encore parce qu'elle était l'ouvrage de mon père qui l'avait, pour ainsi dire, régénérée ${ }^{37}$. " Pour ces auteurs de la campagne du Maine, la terre est un bien essentiel, qui retient leur attention et à laquelle ils consacrent des livres de comptes et de nombreuses descriptions. Dans leurs écrits, les dernières nouvelles de la province et les faits marquants du moment se mêlent ainsi aux faits plus personnels.

31. Arch. dép. de la Sarthe, 26 J 194. Notes d'un paysan, p. 1.

32. Ibidem, p. 25.

33. Arch. dép. de la Sarthe, 1 J 83. Livre journal de M. Guyot, sieur de l'Hommaie.

34. Ibidem.

35. Esnault, Gustave-René, Mémoires de René-Pierre Nepveu..., op. cit., p. 101.

36. Froger, Louis, Histoire généalogique de la famille de Vanssay, Mamers, Fleury et Dangin, 1890, p. 107-108.

37. Esnault, Gustave-René, Mémoires de J.-B.-H.-M. Le Prince d'Ardenay, avocat au Parlement, négociant, juge-consul et maire du Mans, Le Mans, Leguicheux-Gallienne, 1880, p. 166 . 


\section{Les cadres de la vie quotidienne}

La conception et la perception du temps se font à partir du calendrier liturgique. René Desboys du Chastelet, après son séjour forcé à Alger, vers 1642-1643, fait la comparaison avec le calendrier musulman : « Je sçay bien que l'an de grâce est bien plus nombreux que celui de l'Egire, comme le surpassant en cette énnée mil six cens soixante-cinq de quatre cens huit, le turc ne contant de l'Egire que mil deux cens soixante $\&$ un $^{38}$. " Au cours de l'époque moderne, des modifications sont apportées au calendrier julien : en France, en application de l'édit de Paris de Charles IX (janvier 1564), l'année commence au $1^{\text {er }}$ janvier, et non plus à Pâques : c'est un repère liturgique en moins dans le calendrier. Jean Bodreau commence son livre de raison, en 1567, par cette indication : « L'an mil v cs soixante et sept fut l'annee que l'on commensa a compter l'an du premier jour de janvyer ${ }^{39}$. „ L'édit est enregistré par le Parlement de Paris en 1567, Le Mans s'y conforme le 15 janvier $1567^{40}$. Le calendrier révolutionnaire, institué par la Convention le 24 novembre 1793, est appliqué dans les écrits de la fin de la période du corpus, mais plus difficilement : les auteurs notent souvent les correspondances avec le calendrier grégorien à côté. Le Prince d'Ardenay emploie les deux calendriers : «En juillet 1794, le 3 messidor an II, je fus appelé par le conseil municipal à la place de distributeur des secours militaires ${ }^{41}$ ", note-t-il. Dans son récit de la campagne d'Egypte, François-Marie Le Gras du Luart mélange les deux calendriers : « Nous eûmes deux affaires assez sérieuses, la première eut lieu le 5 janvier $1799^{42}$ ", écrit-il d'abord, puis il parle des " 7,10 et 13 floréal ${ }^{43}$ " en page suivante, et ensuite du " 2 prairial an $7^{44}$ ».

La précision dans le temps s'affine au long de la période. Les auteurs essayent de donner avec précision l'heure pour les naissances, peut-être pour l'horoscope de l'enfant ${ }^{45}$. Ainsi, Pierre-Henri de Ghaisne note à la naissance de ses enfants la date, parfois le nom du saint fêté qui est pour beaucoup le seul moyen de dater et de se situer dans le temps : " Le mardi 2 avril 1709, jour de saint François de Paule, ma femme a accouché, au Mans, d'une fille $^{46}$ ", écrit-il. Il précise l'heure et il est le seul des auteurs étudiés à préciser la date selon le calendrier lunaire : "A onze heures du matin, le 21 de la lune de mars, c'est-à-dire la vigile du dernier quartier de la dite lune. " Le

38. Desboys du Chastelet, René, L’Odyssée..., op. cit., p. 201.

39. Arch. dép. de la Sarthe, $1 \mathrm{~J} 364$. Livre de raison de la famille Bodreau, $\mathrm{f}^{\circ} 2$.

40. LEDRU, Ambroise, "Le commencement de l'année dans le Maine après l'édit de Charles IX ", La Province du Maine, septembre 1898, p. 298.

41. Esnault, Gustave-René, Mémoires de J.-B.-H.-M. Le Prince..., op. cit., p. 261.

42. Arch. dép. de la Sarthe, 13F 1877. Le Gras du LuART, François-Marie, Journal historique des faits de l'armée d'Orient rapportés par un militaire de cette armée, p. 3.

43. Ibidem, p. 8.

44. Ibid., p. 9.

45. FoislL, Madeleine, "En son for privé ", Delumeau, Jean, Roche, Daniel (dir.), Histoire des pères et de la paternité, Paris, Larousse, 1990, p. 179-200.

46. Pour cette citation et les suivantes : EsNAULT, Gustave-René, Les livres de famille dans le Maine, tome 1 : Livre-journal de Pierre-Henri de Ghaisne de Classé, conseiller au siège présidial du Mans (1708-1732), Le Mans, Pellechat, 1883, 31 p. 
30 avril 1710, son fils Pierre-Henri naît "à six heures et un quart du matin ", précise-t-il, et « le premier jour du croissant de la lune d'avril ». De même le 10 novembre 1714, soit " le 7 de la lune ", il note la naissance de Louis-René, "à sept heures et demie du matin ". Cette précision dans les heures au quart d'heure près est permise grâce aux progrès de la technique. Les montres et horloges, encore trop onéreuses jusqu'au XVII ${ }^{\mathrm{e}}$ siècle pour franchir le seuil de toutes les maisons, se généralisent assez au cours du XVIII siècle pour être présentes au sein des familles des élites locales qui constituent en grande partie notre corpus. Dupont de la Motte note dans son journal : " L'horloge envoyée de l'Ecole militaire est arrivée en bon état ${ }^{47}$ ", le collège de La Flèche peut se permettre d'investir dans une horloge. Cependant, en tant que particulier, le diariste s'intéresse aux nouveautés, et écrit : " J'ai reçu de M. Le Sante une pendule à secondes ${ }^{48}$ ", améliorant la précision de l'heure, elle est estimée à 500 livres ${ }^{49}$.

Au cours de l'époque moderne, la météorologie n'est pas encore une science, il s'agit simplement d'observations. N'en sont évoqués que quelques exemples, les remarques sur le climat étant très nombreuses dans les ego-documents. Les événements naturels laissent une forte impression sur les consciences; en témoigne le vocabulaire employé : le prêtre Fleury rapporte une " affreuse tempête ${ }^{50}$ "; le chanoine Nepveu dramatise facilement, il assiste à " un ouragan affreux ${ }^{51}$ " lors de l'hiver 1762 au Mans, puis " un vent affreux, comme on n'en avait point vu depuis un temps immémorial $^{52}$ ", secoue la région en décembre 1803. En 1792, Montaron note qu'« il est tombé une gran avalason d'eau penden trois jour ${ }^{53}$ ", la région subit aussi " un grand arogan " le 4 août 1807. Les innovations scientifiques des $\mathrm{XVI}^{\mathrm{e}}$ et XVII $\mathrm{e}^{\mathrm{e}}$ siècles se répandent au cours du XVIII siècle, et permettent une meilleure précision dans les descriptions météorologiques. Un thermomètre et un baromètre se trouvent ainsi au collège de La Flèche en 1773 et 1774 : « Le thermomètre avait descendu depuis Noël à 4 degrés de congélation $^{54}$ ", observe Dupont de la Motte au jour de l'an 1773, et au cours de l'été, il constate que " le thermomètre de Réaumur a monté aujourd'hui à 25 degrés ${ }^{55}$ ". Il s'agit d'un thermomètre à alcool, conçu en 1730 par le physicien Réaumur. L'inspecteur du collège s'intéresse à ces instruments et inscrit au cours de l'hiver suivant : « Le baromètre est remonté en 24 heures de $27^{\circ} 1$ à $27^{\circ} 11^{56}$. "Ses indications plus précises montrent une évolution

47. Boisson, Didier, Le journal de Stanislas Dupont..., op. cit., p. 1465; septembre 1773.

48. Ibidem, 28 septembre 1774, p. 220.

49. Ibid., note 14, p. 220.

50. FleURY, Jacques-Pierre, Mémoires sur la Révolution, le Premier Empire, Paris, Victor Palmé, ou Le Mans, Leguicheux-Gallienne, 1874, p. 73.

51. Esnault, Gustave-René, Mémoires de René-Pierre Nepveu..., op. cit., p. 21.

52. Ibidem, p. 413.

53. Pour cette citation et la suivante : Notes d'un paysan, op. cit.

54. $1^{\mathrm{er}}$ janvier 1773, Bolsson, Didier, Le journal de Stanislas Dupont..., op. cit., p. 113.

55. 13 août 1773. Ibidem, p. 143.

56. 27 février 1774. Ibid., p. 177. 
de l'étude du climat : on passe de la simple observation à une science plus poussée, nécessitant des instruments de mesure.

À l'image du temps qu'il fait, les prix, principalement du blé, et le cours des monnaies occupent une grande place dans les écrits du corpus. Dès le milieu du XVI ${ }^{\mathrm{e}}$ siècle, le prix du blé augmente rapidement, les hausses brutales se multiplient. Dans le Maine, suivant le livre de raison de Jean Bodreau et le journal de Jean de Courbefosse, l'année 1573 semble particulièrement chère; le premier constate le 24 avril que " aux Halles du Mans [...] l'on vendoit le bled seigle quarante sols le boesseau [...] il hausa de prix et fut vendu soixante sols le boesseau ${ }^{57}$ ", et le second note à la Saint-Jean : "Le boesseau de seigle vallait jusques à LX sols et continua longtemps ${ }^{58}$." "

Examiner les comptes d'un auteur permet de mettre en évidence son rapport à l'argent et ses réseaux financiers : est-il débiteur ou créditeur? Les comptes personnels révèlent les dettes et rentes de l'auteur. Guyot de l'Hommaie gère les baux et fermes de ses terres : " J'ai receu de Bihoreau pour deux années de la ferme des champs à lasne ${ }^{59}$ ", note-t-il en août 1697. Ses comptes personnels comprennent aussi ses dettes particulières envers les divers artisans de la région qu'il embauche; le dimanche 29 janvier 1719 , il écrit qu'il a " conté de toutes choses avec Richard, charpentier, et au moyen du payement de quatre ving seize livres quinze sols, et un boisseau de bled qu'il avoit eu à Aubigné, je demeuré quitte envers luy ${ }^{60}$ ". Entre 1649 et 1679, le curé Louys Pousteau tient un " mémoire des rantes ", que lui doivent ses paroissiens de Saint-Léonard-des-Bois : « Premierement Tommas Durand soixante et dix soubz, La veuve Sanson Sortin sinquante soubz, Jean Denizé quarante 8 soubz, Harry Garcon $3 \# 15$ soubz ${ }^{61}$. " Sa position dans le village lui permet d'avancer quelques sommes. Certains le remboursent aussi en journées de travail. Pour sa part, Louis Montaron semble capable au début du XIX ${ }^{\mathrm{e}}$ siècle de prêter de grosses sommes, ainsi à son frère Michel " lassomme de onze cen cinqante franc ${ }^{62}$ ". Avoir une bonne organisation des comptes, c'est montrer que l'on maîtrise ses affaires. Les auteurs du corpus manient pour la plupart des sommes d'argent relativement importantes, ou bien sont les créanciers de leur entourage. Notables urbains ou ruraux, ils peuvent se permettre de faire des investissements considérables, et tiennent les comptes de leur maison dans un souci d'organisation.

Quelle place accorde l'auteur à sa maison dans ses écrits? On n'y trouve que des allusions, lors des naissances, lors des réparations et de transformations dans la maison ou dans la ville. Ici, il n'y a pas de cas d'habitat rural pauvre, mais très majoritairement des maisons urbaines, ou des propriétés

57. Arch. dép. de la Sarthe, $1 \mathrm{~J} 364$. Livre de raison de la famille Bodreau, $\mathrm{f}^{\circ} 8$.

58. Arch. dép. de la Sarthe, 7 J 34. Extraits du livre-journal de Jean de Courbefosse.

59. Livre journal de M. Guyot, sieur de l'Hommaie.

60. Ibidem.

61. Journal de Louys Pasteau.

62. Notes d'un paysan, op. cit., p. 77. 
à la campagne. Ces maisons ont des noms, ou une localisation bien précise donnée par leur propriétaire. Le titre du livre de famille de Pierre Bellenger donne son adresse au Mans en 1533 : « Maistre Pierre Bellengier demeurant à la Porte ferrée ${ }^{63}$. " Certains auteurs ou familles d'auteurs ont laissé leur nom à un hôtel : l'hôtel Ménard-de-la-Groye, datant du XvIII ${ }^{\mathrm{e}}$ siècle, se situe 6 rue du Bouquet, au Mans. La fierté et le grand attachement envers la demeure se voient à travers le souci manifesté par son heureux possesseur de la bien mettre en valeur. Jean-Baptiste Le Prince d'Ardenay estime, à 40 ans, que lui et sa femme méritent de "vivre un peu pour nous-mêmes et de nous procurer une certaine liberté qui nous manquait ${ }^{64}$ ", et le meilleur moyen, pour lui, est évident : «En conséquence, je songeais sérieusement à acquérir une maison ", être propriétaire et quitter la demeure paternelle. Il achète une maison au Mans, place des Halles, et s'y installe en 1778, « fier et bien content d'avoir pignon sur rue ". Les auteurs sont propriétaires ou locataires de maisons cossues, en changent régulièrement lorsqu'il ne s'agit pas d'un bien héréditaire, tout en restant la plupart du temps dans la même aire géographique.

Les objets de la vie quotidienne sont parfois décrits, ou simplement évoqués. Les objets nécessaires sont ceux dont on a constamment besoin. Le curé Louys Pasteau fait un inventaire du linge qu'il a " dans la trousse : Premier 3 drap deux de brin et un gros. 3 nappes deux grose eunne douze. 6 chemize, trois grose et 3 de brin. Huit mouchouers de poche ${ }^{65}$ ". Les vêtements et les draps sont de première nécessité. Plus aisé que la plupart de ses ouailles, Pousteau a plusieurs chemises, mais leur qualité, ainsi que celle des draps et nappes, laisse penser qu'il ne vit pas richement. De même, lorsqu'on lui fait quitter sa paroisse, à la Révolution, Fleury prend avec lui le strict nécessaire : " J'emportoi seulement trois chemises, quelques mouchoirs de poche, bas, bonnet, mes bréviaires, un bâton ${ }^{66}$ ", écrit-il, ce qui, à un siècle d'écart, correspond à l'inventaire de Pasteau.

Les objets de loisir sont indices de luxe, ils permettent de quantifier la place du superflu au sein d'une famille. Six mois après son mariage, PierreHenri de Ghaisne note dans son journal qu'il offre à son épouse " un petit coffre de velours rouge garni de bandes de cuivre, doré en dehors, et de galon d'or en dedans, qui m'a cousté 19 livres à la vente du sieur Poupart, cirier ${ }^{67}$ ». La description d'une robe qu'il offre à sa femme deux ans plus tard montre l'aisance du couple : " J'ay donné à ma femme, le 24 janvier 1711 , un habit de damas blanc à fleurs d'or, la jupe de velours noir et le

63. ChAppéE, J., "Bellanger, un livre de famille manceau (1533-1667) ", La Province du Maine, t. 11 (1903), p. 354-359; 378-383 et t. 12 (1904), p. 31-37.

64. Pour cette citation et les suivantes : Esnault, Gustave-René, Mémoires de J.-B.-H.-M. Le Prince..., op. cit., p. 135.

65. Journal de Louys Pasteau, op. cit.

66. FlEURY, Jacques-Pierre, Mémoires sur la Révolution ..., op. cit., p. 178-180.

67. 3 janvier 1709. Esnault, Gustave-René, Les livres de famille dans le Maine, tome 1 : Livre-journal de Pierre-Henri de Ghaisne..., op. cit. 
jupon de moire d'argent bleue et couleur de rose ${ }^{68}$ ", il la paye 250 livres à Paris. Le 10 janvier 1705, c'est de l'argenterie que le sieur de l'Hommaie offre à son épouse : " J'ay achepté au Mans une demie douzaine de cuillers et fourchettes d'argent pour 163\# et 3\# 12s. la graveure ${ }^{69}$." Dans la même période, pour comparaison, Ponce Millet achète une « cuillère et fourchette d'argent présentées dans un étui pour $17 \mathrm{~L} \mathrm{10s.}{ }^{70}$ ". Fourchettes et cuillères sont devenues courantes dans la société au cours du XVII ${ }^{\mathrm{e}}$ siècle, ici, c'est leur matière qui en fait une marque d'opulence. Pour sa demeure de l'Hommaie, il commande à son menuisier, M. Hyllaire, " deux petites tables à mettre sous des miroirs avec des tiroirs et un volant de $\operatorname{sapin}^{71} "$; les miroirs sont des signes de luxe. De même, l'inventaire des biens aux Rouaudières avant le mariage d'Henriette avec Louis-Joseph de Vanssay, en 1755, indique " une boîte où sont des couleurs pour peindre, $6 \# 72$ ".

L'étude des comptes, la description des maisons et des objets de la vie quotidienne confirment l'appartenance de ces auteurs d'ego-documents à l'élite de leur société. On a vu que leurs écrits s'inscrivent dans le cadre de la province du Haut-Maine, les événements intéressant le plus les auteurs sont ceux qui ont lieu dans les régions proches, qu'ils connaissent. Cependant, pour son auteur ou pour son lecteur, l'écrit du for privé constitue avant tout une chronique familiale.

\section{Une chronique familiale}

La famille est le pivot de tout ego-document. Elle est la base de la société d'Ancien Régime, et l'écrit du for privé est destiné à la famille, car il ne concerne qu'elle. On la retrouve pour chaque naissance ou baptême, chaque mariage ou décès évoqués. L'ego-document sert aussi de preuve, pour mettre en avant la grandeur de la famille, à travers les généalogies et les commentaires sur le lignage donnés par les auteurs successifs d'un écrit. La naissance, le mariage et la mort sont les trois étapes de la vie, encadrées par l'Église à travers les sacrements du baptême et du mariage ainsi que de la sépulture.

\section{«Naître, se marier, mourir ${ }^{73}$ "}

En général, les auteurs évoquent peu leur naissance. Symon Le Gendre et Michel Le Vayer commencent leur écrit en donnant leur date de nais-

\footnotetext{
68. Ibidem.

69. 10 janvier 1705. Livre journal de M. Guyot, sieur de l'Hommaie.

70. MARBY, Jean-Pierre, "Le prix des choses ordinaires, du travail et du péché : le livre de raison de Ponce Millet, 1673-1725 ", Revue d'Histoire Moderne et Contemporaine, octdéc 2001, p. 7-31.

71. 8 mars 1704. Livre journal de M. Guyot, sieur de l'Hommaie.

72. Arch. dép. de la Sarthe : 1 Mi 3 R 11.

73. Expression empruntée à René PlEssix, Au fil de la vie. Naître, se marier, mourir dans

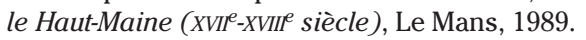


sance: "Je suis né du mariage de défunts Guillaume Le Gendre, et de Michelle Chenon, sa seconde femme, la nuit d'entre le jour de Noël et SaintEtienne, mil Ve vingt trois ${ }^{74}$ ", dit le premier; " Je suis ney le 28 avril $1620^{75}$ ", écrit simplement le second. Alors que Jean Bodreau note dans le livre la naissance de son fils Julien, «le samedy treiziesme jour de septembre mil cinq cens soixante douze ${ }^{76}$ ", ce dernier rajoute : "C'est le jour de ma naissance ». La naissance est encore empreinte de beaucoup de superstitions. En 1776, à propos d'une femme ayant accouché d'une fille, le chanoine Nepveu assure que "suivant la lune, elle doit avoir un garçon le premier enfant qu'elle aura, car la lune a changé le lendemain de sa couche ${ }^{77}$ ". Venant d'un homme d'Église, ces propos pourraient choquer, mais il rajoute que " c'est une remarque que l'on fait depuis longtemps ${ }^{78}$ ".

La plupart des statuts synodaux et une déclaration royale de 1698 imposent le baptême du nouveau-né dans les 24 heures suivant la naissance. Ainsi, en 1775, Ménard de la Groye regrette le retard dans le baptême de son fils François : " Ma femme est accouchée d'un garçon qui n'a été baptisé que le lendemain trois dud mois de may ${ }^{79}$ ", écrit-il. Une dispense est nécessaire pour retarder la cérémonie à l'église, mais en attendant, l'enfant est ondoyé. Même avant cette déclaration, les parents n'aiment pas repousser le baptême. Marguerite Bouteiller, née le 23 décembre 1690, est ondoyée « en conséquence de la permission de monseigneur l'évêque du Mans de différer les cérémonies du baptême pendant six moys [...] son parrain et sa marraine sont actuellement dans la ville de Paris ${ }^{80}$ ". C'est au moment du baptême que l'enfant reçoit son nom, de ses parrain et marraine. En 1593, un enfant Le Vayer est donc « nommé Anne en considération que la dite dame [sa marraine] porte semblable nom ${ }^{81}$ ", un autre est "nommé René en mémoire de son ayeul maternel ". Chez les Le Gendre, un neveu est " nommé Guillaume par ledit Chenon pour défunt Guillaume Le Gendre, mon père ${ }^{82}$ ", dit Symon en 1551. Le choix du prénom par le parrain implique la transmission d'une mémoire familiale, ainsi que la protection du parrain et du saint patron. Il existe quelques cas exceptionnels; un enfant non baptisé ou quasiment mortné n'est pas nommé. Jacques II Le Divin note par exemple le 17 mars 1666 la mort d'un fils, " qui ne vescut qu'une heure; il fut babtizé et point nommé ${ }^{83}$ "; Pierre-Henri de Ghaisne évoque " [s] a fille Anonime ${ }^{84}$ ".

74. " Le livre de raison de la famille Le Gendre ", art. cit.

75. BARET, René, Le Livre de raison de Michel Le Vayer, " grand doyen " du Mans, prédicateur et aumônier de la Cour (1620-1691), Laval, Madiot, 1971, 38 p.

76. Livre de raison de la famille Bodreau, $\mathrm{f}^{\circ} 7$.

77. Esnault, Gustave-René, Mémoires de René-Pierre Nepveu de la Manouillère, op. cit., p. 254.

78. Ibidem, p. 249.

79. Livre de raison de Ménard de la Groye.

80. Livre de raison de la famille Bouteiller-Le Prince.

81. René BARET, Le Livre de raison de Michel Le Vayer..., op. cit.

82. "Le livre de raison de la famille Le Gendre ", art. cit.

83. CHAPPÉE, J., " Bellanger, un livre de famille manceau (1533-1667) ", art. cit.

84. 11 février 1718. EsNault, Gustave-René, Les livres de famille dans le Maine... op. cit. 
Peu d'auteurs font allusion à leurs enfants une fois ceux-ci nés, et même au XIX ${ }^{\mathrm{e}}$ siècle le curé Fleury estime qu' " un père et une mère doivent être sérieux avec leurs enfans, et ne leur jamais trop témoigner extérieurement, surtout dans leur bas âge, l'attachement qu'ils leur portent ${ }^{85}$ ". On ne les retrouve dans les écrits du for privé que lorsqu'ils ont trouvé leur condition, soit pour une évocation de leur mariage, soit pour un décès inattendu. Le temps de l'enfance est négligé, le bébé est surtout vu comme un futur adulte à former. Cependant, certains adultes s'intéressent à l'enfant. À la fin du XVII ${ }^{e}$ siècle, le père de René de Vanssay est ainsi " attentif à donner unne éducation convenable à ses enfants ${ }^{86}$ ", le chanoine Nepveu reproche à un père d'envoyer ses enfants au couvent pour ne pas avoir à s'en occuper : " M de Blanchardon a beaucoup de reproches à se faire de la manière avec laquelle il en agit avec ses enfants ${ }^{87}$ ", écrit-il en 1791. Le rapport à l'enfant évolue au cours de l'époque moderne, et les récits d'enfance apparaissent avec Rousseau. L'enfant est considéré en tant qu'individu, et non plus comme maillon (remplaçable) de la famille et du nom porté. La mort d'un enfant peut alors marquer profondément les parents : " Depuis ce temps-là, ma sœur n'a pas eu d'enfant ${ }^{88}$ ", raconte Nepveu. On reconnaît ici l'enfant en tant que personne à part entière. Les couples sans enfants, comme les Le Prince d'Ardenay, restent des cas exceptionnels. Henriette Edme des Rouadières semble déplorer cet état : " Je n'ai point d'enfants ${ }^{89}$ ", dit-elle dans les années 1770; elle se consacre à l'éducation de sa nièce.

Le mariage est une étape quasi obligée de la vie. Loin des clichés véhiculés, dans une union la relation entre conjoints importe beaucoup. Plusieurs facteurs entrent en jeu, d'abord la conformité d'âge ${ }^{90}$; lors d'une proposition de mariage avec une femme riche, René du Guesclin décline l'offre : "Son âge m'empêcha d'y penser ${ }^{91}$ ", raconte-t-il : vers 1670, il doit avoir 25 ans et la dame est, selon ses termes, " avancée en âge ". "C'est un mariage d'inclination ${ }^{92}$ ", écrit Nepveu dans son journal à l'occasion du mariage de $\mathrm{M}^{\mathrm{lle}}$ Dagues et M. Raison en 1780 : la conformité de sentiments préoccupe les intéressés. Il faut toutefois sacrifier à la conformité de situation : un mariage se fait raisonnablement, et l'on blâme les mésalliances. Si le mariage forcé est condamné par l'ordonnance de Blois de 1579, le mariage sans consentement des parents est interdit aux mineurs; les mariages entre cousins sont prohibés. Jacques Le Vayer, aîné d'une branche de la famille dont le père est mort, épouse en février 1677 sa cousine Renée Le

85. FleURY, Jacques-Pierre, Mémoires sur la Révolution..., op. cit., p. 470.

86. Livre de raison de René de Vanssay.

87. Esnault, Gustave-René, Mémoires de René-Pierre Nepveu de la Manouillère, op. cit., p. 243.

88. Ibidem, p. 38.

89. EDME DES RouAudières, Henriette, Confidences générales et particulières, p. 266.

90. Conformité d'âge, de situation, de sentiments : termes empruntés à Anne FILLON, Les Trois bagues aux doigts, amours villageoises au XVIII siècle, Paris, R. Laffont, 1989.

91. Extraits des mémoires de Du Guesclin.

92. Esnault, Gustave-René, Mémoires de René-Pierre Nepveu..., op. cit., p. 375. 
Boindre, " en vertu de dispense obtenûe de Cour de Rome, mariage fatal, fait contre toutes les loix eternelles ${ }^{93}$ ", affirme Michel Le Vayer, qui appuie son jugement sur saint Augustin, les théologiens anciens et modernes, les décisions pontificales et le droit canon. C'est un " mariage incestueux, projetté, conclus et consommé contre mes avis et remonstrances ", que le reste de la famille condamne aussi. La famille, et non seulement les parents, est censée intervenir dans le choix des époux, et le mariage sans consentement va à l'encontre de ce droit, d'où le mécontentement des parents proches. De même, Dupont de la Motte ne cautionne pas son frère, qui épouse sa maîtresse enceinte : "Je ne donne pas les mains à cet arrangement ${ }^{94}$ ", note-t-il. Son refus est guidé par le souci de sa réputation dans la petite ville de La Flèche, il se justifie : " Tout le monde pensait que c'est, de concert avec moi, que s'est faite cette publication de bans; j'ai fait opposition à la célébration afin de me justifier "; alors que le diariste lui-même s'est marié en janvier 1763 avec Marie-Françoise Walpurge Scherbeck de Froberg, sans le consentement des parents de celle-ci, ni celui des curés de leur deux paroisses ${ }^{95}$.

À la résignation face à la mort inévitable succède au cours de l'époque moderne une vision de la mort comme rupture dans l'existence. La belle mort, la qualité du deuil des proches et le prestige de l'inhumation importent. Lorsque Jean de Courbefosse est invité aux funérailles de Jehan Brouiller, archidiacre du Mans, on lui offre " une paire d'heures en parchemin couvertes de velours violet ${ }^{96}$ ". « Il y avait un enterrement splendide ${ }^{97}$ ", s'extasie Nepveu à la mort de madame de Fondville en 1786. Le lieu d'inhumation relève aussi du prestige du mort : un des oncles de Nepveu est enterré « dans la chapelle où est le caveau de MM. Portail; comme il n'y en a plus du nom et que nous sommes les plus proches parents, nous avons droit à la dite cave ${ }^{98}$ ", annonce-t-il. Les funérailles restent un moment difficile, et celles de son grand-père ont beaucoup marqué Jean-Baptiste Le Prince d'Ardenay enfant : " Je ne sais comment je pus le soutenir ${ }^{99}$ ", se rappelle le mémorialiste. La mort marque en tout cas les auteurs lorsqu'elle n'est pas prévue : « Le mardy 22 avril 1659, Louis de Champlais, baron de Courcelles, mourut sur le menuict, et l'avois veu le lundy 14 avril quy estoit le fairier de Pasques ${ }^{100}$ ", s'étonne le rédacteur du livre de la famille Champlais.

93. Pour cette citation et la suivante : BARET, René, Le Livre de raison de Michel Le Vayer, op. cit.

94. Pour cette citation et la suivante : 15-16 octobre 1774, BoIsson, Didier, Le journal de Stanislas Dupont..., op. cit., p. 224.

95. Ibidem, p. 25. Voir aussi Arch. Dép. de la Sarthe, registres Gg 1 à 6 (1673-1790), p. 380 , col.2, pour l'acte de confirmation du mariage de Stanislas Dupont de la Motte, le $1^{\mathrm{er}}$ septembre 1775 , qui fournit ces informations.

96. 15 novembre 1549, extraits du livre-journal de Jean de Courbefosse.

97. Esnault, Gustave-René, Mémoires de René-Pierre Nepveu... op. cit., p. 158.

98. Ibid., p. 25-26.

99. Esnault, Gustave-René, Mémoires de J.-B.-H.-M. Le Prince... op. cit., p. 16-17.

100. BastaRD D'Estang, François de, "Un Livre d'heures de la Maison de Champlais ", Revue Historique et Archéologique du Maine, t. XXIV, 1888, 75 p. 
À la mort de chacun de ses deux parents ou de son épouse, le fils ou l'époux qui tient l'ego-document exprime son dévouement et ses sentiments envers eux. Cette mort permet d'avoir une rapide description, évidemment laudative, du défunt. La mort du père permet de rappeler ses qualités d'homme : François de Champlais a donc "suivy ses prédécesseurs en valeur et prudence, craint et aimé de ses sujets ${ }^{101}$ ", le 2 octobre 1616. Le 13 juin 1662, Julien II Bodreau est « decede en bon chrestien et bon catholique et ayant receu tous les sacremens de l'eglise ${ }^{102}$ ", écrit Charles, qui l'appelle "mon cher pere». Des expressions de deuil sont courantes, comme : "À mon grand regret et a ma grande perte. » Le Prince d'Ardenay raconte que lui et ses frères et sœurs étaient " trop accablés de douleur ${ }^{103}$ ", lors de la mort de leur père en 1711. Lors du décès de la mère, on rappelle ses vertus maternelles et chrétiennes : dans sa Vie de $\mathrm{M}^{\mathrm{re}}$ René de Vanssay escritte par lui mesme, René déplore la disparition de sa mère alors qu'il a à peine 5 ans : " Il eût le malheur de perdre Mme sa mère en l'année 1690 le 19 avril ", dit-il de lui. Au XVII ${ }^{\mathrm{e}}$ siècle, Michel Le Vayer emploie les termes : " Madame Renée Vasse ma tres honorée mère ${ }^{104}$. " On insiste surtout sur sa dévotion, qualité que l'on retrouve moins lors de la louange du père. La mère de Victor Le Peletier est donc enterrée en 1526 dans l'église paroissiale, "à l'endroict où est la selle anciennement où elle se retiroyt assistant au divin service ${ }^{105}$ ", écrit-il; « Sa bonté sa piété et sa charité l'on faict regretter de tous et particulièrement de ceux de sa famille et de moy son fils unique $^{106}$ ", dit Julien Bodreau de sa mère. L'annonce de la mort de l'épouse répond aux mêmes exigences; en tant que mère, elle est pieuse et pleine des qualités maternelles. Pierre Bellenger note sobrement : " Margarite de la Porte, ma femme, mourut le jour sainct Thomas, xxì jour de décembre 1548, et fut enterrée à Sainct-Benoist ${ }^{107}$. " Au contraire, un siècle plus tard, Julien II Bodreau l'appelle " ma tres chere et honorée femme ${ }^{108}$ " et s'étend longuement sur sa personne; il écrit qu'il souhaite être inhumé près d'elle et ses parents, " aupres des corps que j'ay les plus cheris et honore en ce monde ". La mort est pour ces auteurs la conclusion d'une vie chrétienne. Ces étapes d'une vie individuelle enrichissent les commentaires plus généraux apportés par les membres de la famille à propos du lignage.

101. BASTARD D'Estang, François de, " Un Livre d'heures de la Maison de Champlais ", art. cit.

102. Pour cette citation et les suivantes : Livre de raison de la famille Bodreau, $\mathrm{f}^{\circ} 223$.

103. Esnault, Gustave-René, Mémoires de J.-B.-H.-M. Le Prince d'Ardenay, op. cit., p. 161162.

104. BARET, René, Le Livre de raison de Michel Le Vayer, op. cit.

105. 3 janvier 1526, Esnault, Gustave-René, Les livres de famille dans le Maine, tome 2 : Livre de raison de la famille Peletier, Le Mans, Pellechat, 1890, 32 p.

106. Livre de raison de la famille Bodreau, $\mathrm{f}^{\circ} 112 \mathrm{v}^{\circ}-113 \mathrm{v}^{\circ}$.

107. CHAPPÉE, J., " Bellanger, un livre de famille manceau (1533-1667) ", art. cit.

108. Pour cette citation et la suivante : Livre de raison de la famille Bodreau, $f^{\circ} 148$ $152 \mathrm{v}^{\circ}$. 


\section{Le prestige familial}

La généalogie intègre l'auteur à l'histoire de la famille et définit son identité. Rarement commandée à un généalogiste professionnel, la généalogie est soit faite par l'auteur de l'ego-document, soit récupérée d'un membre de sa famille. Cette pratique implique la contribution de souvenirs de famille, le recours certain à l'imagination et/ou à la documentation familiale; mais il est parfois difficile de savoir quelles sont les sources utilisées autres que la mémoire familiale. Toutefois, " put se vanter la ditte famille de Vanssay estre des meilleures et plus anciennes noblesses qui sont en France [...] ainsy qu'il se peut voir par pièces authentiques ${ }^{109}$ ", écrit René de Vanssay au XVIII siècle. On apporte donc aussi des preuves d'ancienneté aux généalogies, qui deviennent nécessaires face aux enquêtes de noblesse sous Louis XIV. Dans son livre de raison, René de Vanssay raconte les origines de la châtellenie de la famille, il fait allusion, comme justification de leur établissement dans la région, à " une letre antique approuvée par un Foulque abbé de Sct Calais qui vivoit l'an de grâce 1037 ». Placée en début d'un livre de raison, ou même de mémoires, la généalogie justifie la place de l'auteur dans la société et dans un cadre familial prestigieux (soit par son ancienneté, sa vertu ou ses connaissances), le récit suivant cette généalogie montre la façon dont la vie de l'auteur contribue à ce prestige familial ${ }^{110}$, la façon dont il s'inscrit dans sa lignée. C'est une des passions de René II du Guesclin, appartenant à la vieille noblesse du royaume, reprise par son fils René III, le mémorialiste. Progressivement, la généalogie n'est plus l'apanage des livres de raison de la noblesse, et les familles aisées du Tiers se prêtent à l'exercice. Julien Bodreau, le notaire, note ainsi dans son livre de raison " la genealogye desdits Bodreau et Termeau ${ }^{111 ~ " ; ~ i l ~ c o m m e n c e ~}$ à son grand père Jean Bodreau, un marchand. De même, l'avocat Charles Bourgouing commence ainsi son livre de famille, rédigé au XvII ${ }^{\mathrm{e}}$ siècle : " Généalogie de $\mathrm{M}^{\mathrm{rs}}$ les Huets originaires du bourg de Restigné en Touraine dont moy Charles Bourgoing Con ${ }^{\text {er }}$ et advocat du roy en l'eslection de cestte ville du Chaû du Loir suis sorty à cause de tres honeste femme Jacquine Huet ma mère ${ }^{112}$ "; celle-ci commence en l'an 1490, et remonte jusqu'à lui et ses enfants.

Les armes et la devise de la famille prouvent sa noblesse et accompagnent parfois la généalogie. Dans le livre d'heures de la famille de Champlais se trouvent plusieurs enluminures, dont un Couronnement de la Vierge. Dans les bras de l'ange, on peut remarquer les armoiries de François de Champlais et son épouse Marie de Bastard. On trouve la devise des Vanssay dans le livre de raison de René : " La vertu à notre aage Devanssay ${ }^{113}$ ", qui,

109. Pour cette citation et la suivante : Livre de raison de René de Vanssay.

110. Voir à ce sujet Frédéric BRIOT, Usage du monde, usage de soi : enquête sur les mémorialistes d'Ancien Régime, Paris, Seuil, 1994, 296 p.

111. Livre de raison de la famille Bodreau, $\mathrm{f}^{\circ} 23 \mathrm{v}^{\circ}$

112. Livre de raison de Charles BouRGouing (MS B 533).

113. Livre de raison de René de Vanssay. 
chez Froger, devient : " L'âge a dedans nous l'âge de Vancé ${ }^{114}$. " La femme de Pierre-Henri de Ghaisne fait un "placet en broderie où sont les armes des Raguindel ${ }^{115}$ ", c'est-à-dire de sa famille à elle. Ces armes sont " d'azur à la bande ou face d'argent, au croissant d'or en pointe, qui sont sur la porte de la rue Hallé, à la droite en entrant".

Les alliances entre lignages contribuent évidemment à la grandeur de la famille. Le livre de raison des Champlais appartient à la branche de la Masserie. Cela n'empêche pas l'auteur de faire allusion à la branche de Champlais-Courcelles pour mettre en valeur les alliances de la famille, notamment à la mort de Louis de Champlais, baron de Courcelles, en 1659 : "Le dict baron de Courcelle puiné de séans et sa dernière femme avait nom Marie de Villeroy, sœur de M. le maréchal de Villeroy ${ }^{116}$. " Louis de Champlais est seigneur baron de Courcelles, conseiller du roi, maréchal des camps et armées du roi, lieutenant-commandant de l'artillerie en Italie, lieutenant général au gouvernement de Lyon, Lyonnais, Forez et Beaujolais, et il a épousé Marie de Neufville de Villeroy, sœur du maréchal ${ }^{117}$. L'oublier dans le livre de la famille aurait été une faute pour la transmission du prestige familial.

Dans le Maine, certaines des familles de la noblesse revendiquent dans leurs écrits une ascendance des ducs de Bretagne. Ainsi, chez les Champlais, les ancêtres cités sont de toute façon " tous sortis de Champelais baillé par empanage aux Champelais par le duc de Bretaigne qui avoit seze filz et seze filles, et fut celluy qui fist la foy et hommage, comme duc de Bretagne, à Dagobert roy de France ${ }^{118}$ ". La maison de René de Vanssay " est sortie d'un compte [sic] de Châteaugris cadet des ducs de Bretagne ${ }^{119}$ ".

Raconter la vie de l'autre, les événements ayant eu lieu dans la province ou dans la famille occupe une large part de l'ego-document. Reste à savoir quelle est la place que se consacre l'auteur au cœur de son écrit, quand on sait que le récit à la première personne n'est pas forcément le récit de la vie privée de son auteur.

\section{Comment exprimer l'intime à l'époque moderne?}

Écrire en son for privé, est-ce écrire sur son for intérieur? Cette dernière partie va permettre de s'interroger sur ce qu'est l'intimité, le privé, et la façon dont ils s'expriment au cours de l'époque moderne dans les ego-documents. Il convient pour cela de procéder par couches successi-

114. Froger, Louis Histoire généalogique de la famille de Vanssay, op. cit., p. 4.

115. Pour cette citation et la suivante : Esnault, Gustave-René, Les livres de famille dans le Maine, tome 1 : Livre-journal de Pierre-Henri de Ghaisne de Classé, op. cit.

116. BastaRD D'Estang, François de, "Un Livre d'heures de la Maison de Champlais ", art. cit.

117. CoRDONNIER, Paul, Les personnages célèbres du Maine au XVIr siècle, Le Mans, Monnoyer, 1938.

118. BastaRD D’Estang, François de, « Un Livre d'heures de la Maison de Champlais ", art. cit.

119. Livre de raison de René de Vanssay. 
ves qui constituent la personne : la vie professionnelle d'abord, puis la vie privée, et enfin le moi lui-même : du XVI ${ }^{\mathrm{e}}$ au XVIII ${ }^{\mathrm{e}}$ siècle, parle-t-on vraiment de soi dans un écrit du for privé?

\section{La vie professionnelle}

Touche-t-on à l'intime dans la description de la vie professionnelle? Fleury parle du " bonheur de célébrer ${ }^{120}$ " la messe de Pentecôte au Mans. On suit l'évolution de la carrière de Jacques Le Divin à travers son livre de famille : "J'esté seulement pour lors conseiller au présidial du Mans ${ }^{121}$ ", dit-il lorsqu'il épouse Louise Le Large, en 1607. Le titre de son livre le dit " lieutenant particulier au présidial du Mans ", et à sa mort, en 1657, son fils Jacques II Le Divin rajoute qu'il est anobli, " escuyer, conseiller du roy en ses conseils d'estats, sy devant lieutenant particulier au siège ". Le Prince d'Ardenay est d'abord destiné à la magistrature, mais il suit son goût et abandonne ce projet : "Je ne pouvais m'habituer au style barbare de la chicane, aux formes ennuyeuses de la procédure et au galimatias de tous les actes d'un procès ${ }^{122}$. " Ce qu'il a appris lui est cependant utile pour le mettre " en état d'entendre, d'expliquer et de défendre, par la suite, mes propres affaires ${ }^{123}$ ". C'est ainsi qu'il annonce : "Je fus reçu avocat au Parlement, le $1^{\mathrm{er}}$ mars $1761^{124}$." Quand Nepveu raconte ses débuts, il écrit : “ J'ai pris possession de mon canonicat, le cinq février $1759^{125}$ ", puis "Le 14 juin 1767, j'ai commencé à porter la soutane violette ${ }^{126}$ ", le violet étant la couleur de l'évêque, dont dépend le chapitre de Saint-Julien. Les plus bavards sur leur profession sont les membres de la magistrature et du clergé, pour qui la vie professionnelle se confond avec la vie quotidienne. Les témoignages sur la vie militaire et le service de la noblesse d'épée sont plus rares.

Ces témoignages concernent, pour l'ancienne noblesse d'épée, les récits des $\mathrm{XVI}^{\mathrm{e}}$ et $\mathrm{XVII}{ }^{\mathrm{e}}$ siècles. Charles de Chenevières débute son livre de raison par la liste de ses actions militaires : "Le siège de rouen fult en l'an mil cinq cent Quatre vingts et onze à la Toussaints [...] Ou s'est que jy fultz enployé ${ }^{127}$. " Les faits d'armes sont une source de fierté pour la petite noblesse de province, qui les insère fréquemment dans le livre de famille. Né en 1619, René Desboys du Chastelet s'engage comme soldat au siège d'Arras en 1655, il est promu enseigne dans le régiment de M. du

120. FleUry, Jacques-Pierre, Mémoires sur la Révolution..., op. cit., p. 325.

121. Pour cette citation et les suivantes : CHAPPÉE, J., "Bellanger, un livre de famille manceau (1533-1667)", art. cit.

122. Gustave-René Esnault, Mémoires de J.-B.-H.-M. Le Prince..., op. cit., p. 29.

123. Ibidem, p. 31.

124. Ibid., p. 39

125. Esnault, Gustave-René, Mémoires de René-Pierre Nepveu de la Manouillère, op. cit., p. 1.

126. Ibidem, p. 64.

127. Papier journal de Charles de Chenevières. 
Tot de Gonfreville. "De tous les divers métiers, desquels je m'étois mêlé dans le premier effor de ma jeunesse, celui de la guerre ne me rebuta pas le plus ${ }^{128}$ ", assure le Fléchois. Comme il est issu d'une famille de robe, on s'attend plutôt à ce qu'il continue dans la lignée de ses parents. Du Guesclin appartient à une famille d'épée, on apprend dans ses mémoires qu'en 1675, lors de la guerre de Hollande, il est à «Langres où je fus en quartiers d'hiver $^{129}$ ". Les souvenirs de l'armée pour les documents du XVIII ${ }^{\mathrm{e}}$ siècle sont ceux datant de la Révolution ou après, ils proviennent de gens anoblis ou roturiers. Le maître tanneur Mocquereau de la Barrie a par exemple un parcours éclectique : en 1790, il est élu capitaine d'une compagnie de la garde nationale de Loué, il est en 1793 élu capitaine des volontaires de Sillé-le-Guillaume, et fait prisonnier après la défaite des républicains à Vihiers. Ensuite, en 1801, il quitte la tannerie pour succéder à son beaupère, notaire, jusqu'à la majorité de son beau-frère. Au contraire, Le Gras du Luart est un professionnel : il est capitaine des vaisseaux du roi et chevalier de Malte. Il raconte dans son journal les nombreux combats menés par l'armée française en Egypte, par exemple : " Nous rencontrâmes l'armée ennemie composée de cavalerie, avec une flotille dans le Nil, après une escarmouche de quatre heures, l'ennemi fut forcé de prendre la fuite ${ }^{130}$." Son récit alterne comptes-rendus des affrontements et descriptions des régions traversées. Mais ces souvenirs de l'armée sont surtout l'occasion d'avoir la vision de ces auteurs sur le métier des armes et la guerre. Il fait allusion à la campagne d'Égypte comme une " cruelle guerre ", il évoque aussi un "combat sanglant ". Bien qu'il décrive lors de quelques batailles " le tableau le plus affreux [...] un carnage aussi grand ", il n'émet aucune critique, aucune vision négative de la campagne, et se réjouit autant des affrontements que des visites de sites remarquables.

Hormis les ecclésiastiques et les gens de robe, peu d'auteurs décrivent leur vie professionnelle. Parmi ces derniers, un nombre encore plus réduit s'exprime sur leur goût (ou dégoût) pour celui-ci. La profession qu'il exerce ne semble donc pas être un sujet par lequel l'auteur va se révéler. Dans les ego-documents du corpus, s'exprime-t-il d'avantage sur sa vie privée?

\section{La vie privée :}

\section{"J'ay este affligé d'une grande et perilleuse maladie»}

Pour Madeleine Foisil, la maladie n'appartient pas à la sphère du privé, car le malade est entouré des soins des autres ${ }^{131}$. La description que les auteurs d'ego-documents du Haut-Maine font de leurs maladies les place toutefois dans un cadre privé, intime. Dupont de la Motte parle enfin réel-

128. Desboys du Chastelet, René, L’Odyssée, et diversité d'avantures, op. cit., p. 2.

129. Extraits des mémoires de du Guesclin.

130. Pour cette citation et les suivantes : LE GRAS DU LUART, François-Marie, Journal historique des faits..., op. cit.

131. FoISIL, Madeleine, "L'écriture du for privé ", in ARIÈs, Philippe et DuBY, Georges (dir.), Histoire de la vie privée, op. cit., p. 319-357. 
lement de lui lorsqu'il est malade : " Je suis pris par un rhume de cerveau et un mal de tête qui m'empêchent de m'occuper ${ }^{132}$ ", écrit-il dans son journal. Quand Fleury décrit une de ses maladies qui le touche au début du XIX ${ }^{\mathrm{e}}$ siècle : " Une maladie mortelle dérangea tous mes projets; un débordement de bile, une fièvre putride, une lèpre qui me couvrit tout le corps, me conduisirent aux portes du tombeau ${ }^{133}$ ", on touche de près au corps et à tout ce que l'on cache d'habitude. Dans notre corpus, par la place qu'ils occupent, les problèmes de santé font partie des événements que les auteurs considèrent parmi les plus importants à noter. Nepveu s'inquiète après la procession de la Fête-Dieu de 1803 : « J'ai senti que les jambes me manquaient. [...] Voilà la première fois qu'il m'était arrivé la moindre incommodité depuis trente-cinq ans que je faisais cette fonction; il est vrai que j'aurai soixante-onze ans le 3 août prochain ${ }^{134}$ "; et moins d'un an plus tard : " Je suis tombé paralytique du côté droit, le 29 janvier $1804{ }^{135}$. " Michel Le Vayer ne donne aucune précision en écrivant : " En 1653 je fus extraordinairement malade a l'issue des visites de mon grand archidiaconé ${ }^{136}$ "; de même, Julien II Bodreau est " affligé d'une grande et perilleuse maladie ${ }^{137}$ " le 26 février 1658; exprimer l'intensité de la maladie suffit pour la décrire. Elle semble n'intéresser qu'en tant qu'événement particulier dans la vie quotidienne. Les séquelles laissées par ces maladies permettent de mieux connaître les auteurs. Ainsi, Julien I Bodreau raconte : "Je este prevenu d'une grande malladye d'une fluxion qui m'est tombée en la jambe et cuisse droicte $^{138}$ " en 1624. Depuis cette maladie, il est probablement boiteux : " Je ne puis aller qu'avec grande peine et aux environs du logis ", explique-t-il. En marge des descriptions des symptômes et des remèdes, certains auteurs expriment - plus rarement - ce qu'ils ressentent face à la maladie. Fleury parle donc des " souffrances que j'éprouvoi à Londres ${ }^{139}$ ", mais aussi de " la crainte de perdre totalement la vue ». On perçoit aussi l'angoisse de Nepveu de la Manouillère d'être amputé à la suite d'un accident : « Le 24 mai 1776, je me suis blessé le pouce avec un fusil qui m'a crevé dans la main. Je vis le moment qu'on serait obligé de me couper le pouce qui ne tenait que par quelques nerfs ${ }^{140}$ ", il est apaisé après avoir été soigné par un bon chirurgien. Il semble plus facile d'exprimer la douleur physique engendrée par un accident ou une maladie que la douleur psychologique à la suite d'un deuil, encore trop intime pour être consignée sur du papier. L'expression de la souffrance, la peur et la douleur, relèvent en partie de l'intimité de l'auteur, qui confie ses sentiments.

\footnotetext{
132. 6 mai 1773, Borsson, Didier, Le journal de Stanislas Dupont..., op. cit., p. 131.

133. Fleury, Jacques-Pierre, Mémoires sur la Révolution ..., op. cit., p. 231.

134. Esnault, Gustave-René, Mémoires de René-Pierre Nepveu..., op. cit., p. 404.

135. Ibidem, p. 414

136. BARET, René, Le Livre de raison de Michel Le Vayer, op. cit.

137. Livre de raison de la famille Bodreau, $\mathrm{f}^{\circ} 189 \mathrm{v}^{\circ}$.

138. Pour cette citation et la suivante : ibidem, $\mathrm{f}^{\circ} 78$.

139. Fleury, Jacques-Pierre, Mémoires sur la Révolution ..., op. cit., p. 243.

140. Esnault, Gustave-René Mémoires de René-Pierre Nepveu..., op. cit., p. 246.
} 


\section{Se décrire}

Il est très rare de trouver une description physique faite par les auteurs d'ego-documents eux-mêmes. Cependant, faire son portrait est un autre moyen pour les auteurs s'adressant à leurs descendants de transmettre leur mémoire, leur modèle. On parle très peu du corps, on le décrit encore moins; seuls quelques détails apparaissent au détour de la conversation qu'entreprend l'auteur avec lui-même ou son hypothétique lecteur. Grâce aux estimations faites lors de ses ventes successives au souk d'Alger, un début de description de René Desboys du Chastelet se dégage : " Les juifs, et autres sortes d'experts trouvoient mon corps foible, \& plus de vigueur dans les dents qu'ailleurs ${ }^{141}$ ", relatet-il dans ses mémoires. « J'ai maigri ${ }^{142}$ ", écrit seulement Dupont de la Motte à la suite d'une maladie. On a une petite description physique de Mocquereau de la Barrie, quand il raconte lors de la guerre de Vendée : " Pendant ma maladie j'avais fait couper mes cheveux en jacobin ${ }^{143}$ "; et un rapide portrait de JeanBaptiste Le Prince d'Ardenay lorsqu'il décrit les séquelles d'une chute lors de son enfance : «Mon nez enfoncé et mon menton avancé sont une preuve permanente de la violence de cette chute ${ }^{144}$ ", écrit-il.

L'autoportrait physique est à mettre en parallèle avec l'autoportrait moral et/ou spirituel, sorte d'examen de conscience. Il n'y a toutefois aucun rapport à faire entre le physique et le moral : on ne se fie pas à l'apparence extérieure comme représentation de l'intérieur. L'autoportrait physique et l'autoportrait moral se retrouvent dans les journaux de jeunes filles du $\mathrm{XIX}^{\mathrm{e}}$ siècle ${ }^{145}$, et il est curieux de les voir présents chez Henriette Edme, vers 1750 déjà! Les recherches actuelles placent les premiers journaux véritablement intimes, en France, dans les années 1760 : les écrits d'Henriette Edme en deviennent encore plus intéressants. De plus, elle est la seule du corpus à annoncer clairement qu'elle va se décrire physiquement, et la seule à faire un examen de conscience; dans la table des matières, elle titre une partie du Mémorial (1752) " Mon portrait ", pages 99 à 107. Elle écrit donc : " Je ne suis ny grande ny petite; ny belle ny laide; mais j'ai une taille assez noble, avec un air de fraîcheur et de santé qui font qu'en général on me trouve assez bien. " Ce portrait, dans lequel on n'apprend finalement pas grand-chose, n'est évidemment pas aussi développé que les descriptions physiques faites par les jeunes filles du XIX ${ }^{\mathrm{e}}$ siècle, qui peuvent tenir sur un paragraphe ou plus, voire être recommencées plusieurs fois. Ici, c'est le seul portrait écrit que l'on trouvera d'Henriette. Elle en semble satisfaite, et il n'est pas fait pour noter une particularité, un défaut ou un handicap qui la rendrait reconnaissable : il fait transparaître sa noblesse.

141. Desboys du Chastelet, René, L'Odyssée, op. cit., p. 72.

142. 7 janvier 1775, Borsson, Didier, Le journal de Stanislas Dupont..., op. cit., p. 244.

143. Mocquereau de LA BARRIE, Mes trois mois de prison dans la Vendée, p. 46.

144. Esnault, Gustave-René, Mémoires de J.-B.-H.-M. Le Prince d'Ardenay, op. cit., p. 3.

145. Voir LeJEune, Philippe, Le Moi des demoiselles. Enquête sur le journal de jeune fille, Paris, Seuil, 1993; et Rossi, Henri, Mémoires aristocratiques féminins : 1789-1848, Paris, H. Champion, 1998. 


\section{L'expression des sentiments}

L'expression du sentiment permet de dresser un portrait moral, ce qui n'apparaît pas évident pour les auteurs d'écrits privés. Saint-Simon en est un exemple, qui écrit que « les réflexions gâtent bien souvent les mémoires $^{146}$ "; mais il existe heureusement quelques contre-exemples dans le corpus. " J'aime mieux penser que parler ${ }^{147}$ ", confie Henriette Edme vers 1770. Elle se décrit longuement dans son mémorial vingt ans plus tôt : « Il me faut bien du temps et de la réflection pour distinguer le fond des choses. [...] J'apprends avec facilité, [...] j'aime à m'appliquer [...] malgré ma vivacité naturelle ${ }^{148}$ ", écrit-elle. Elle continue : l'éducation, l'entourage " m'avoient accoutumée à me renfermer en moi-même ". " La crainte de valoir moins que les autres ", de même qu'" une discrétion parfaite ", ainsi qu'une " cruelle délicatesse ", et " le cœur triste et l'esprit abbatu ", composent, selon elle, son caractère. "Je deviens un peu mélancolique ${ }^{149}$ ", rajoute-t-elle l'année suivante. Dans son journal, Dupont de la Motte se confie un peu : il évoque « la patience avec laquelle [il] souffre et les boutades et les caprices ${ }^{150} \%$. Les qualités sont davantage mises en valeur que les défauts, que l'on cherche à justifier. Le Prince d'Ardenay dresse son portrait : " Né assez tranquille, je n'aimais pas dès lors et j'ai toujours fui les plaisirs bruyants ${ }^{151}$ ", écrit-il. Il évoque aussi sa " timidité naturelle ${ }^{152}$ ", et sa " juste sensibilité ${ }^{153}$ ". Il est, encore une fois, peu aisé de savoir ce que les auteurs aiment ou n'aiment pas. "Le serment avec restriction me répugnoit ${ }^{154}$ ", dit sans surprise Fleury, qui est inflexible envers le serment constitutionnel exigé des ecclésiastiques.

On constate la grande importance attachée à l'amitié et ses réseaux au cours de l'époque moderne. À la mort d'un chanoine, en 1785, Nepveu en fait l'éloge dans son journal : «C'était un bon et honnête prêtre, aimé dans la société et que j'ai bien regretté; il y avait longtemps que je le connaissais ${ }^{155}$ ». La durée de l'amitié dans le temps en forge la qualité, et la mort, on l'a vu, permet l'expression des sentiments éprouvés envers le défunt. Julien II Bodreau déplore le décès de l'ecclésiastique Jacques Marsault, le 28 novembre 1649 , "il estoit mon inthime amy ${ }^{156}$ ", dit-il. L'amitié intime vient du cœur, comme l'amour, mais est considérée comme étant contrôlée

146. Saint-Simon, Louis de Rouvroy, duc de, Mémoires, t. IV, Bibliothèque de La Pléiade, p. 598 .

147. EDME DES RouAudiÈRES, Henriette, Confidences générales et particulières, p. 158.

148. Pour cette citation et les suivantes : Henriette EDME DES RouAUDIËRES, Mémorial à mon usage particulier (Arch. dép. de la Sarthe, 1 Mi 3 R12).

149. EDME DES ROUAUDIÈRES, Henriette, Réflexions journalières, p. 88.

150. 20 août 1774, Bolsson, Didier, Le journal de Stanislas Dupont..., op. cit., p. 213.

151. Esnault, Gustave-René, Mémoires de J.-B.-H.-M. Le Prince..., op. cit., p. 9.

152. Ibidem, p. 15.

153. Ibid., p. 257.

154. FleURY, Jacques-Pierre, Mémoires sur la Révolution ..., op. cit., p. 77.

155. Esnault, Gustave-René, Mémoires de René-Pierre Nepveu..., op. cit., p. 129.

156. Pour cette citation et les suivantes : Livre de raison de la famille Bodreau, $\mathrm{f}^{\circ} 129$, 154 et 157 . 
par l'esprit et la raison. Le frère de Michel Le Vayer, François, lieutenant général de la sénéchaussée du Mans, et " homme de grande estime et une lumière de son temps ", meurt le 23 décembre 1649. C'est un ami de Julien II Bodreau : " Je l'ay regretté aveq une grande cause parce qu'il m'honoroit de son amitié en consideration que j'avois dedie mon commentaire sur la Coustume du Maine a Monsieur son père "; ami du père, Julien est devenu par conséquent l'ami du fils. Les qualités du mort ami sont mises en avant, la notion de respect est essentielle dans l'amitié. Avec la mise en avant de ces amitiés, le livre de raison devient " livre de réseau ${ }^{157}$ " : l'on choisit plutôt ses amis dans la même classe sociale, et dans le même ressort géographique que les siens. Les sentiments éprouvés envers le réseau d'amis donnent une autre dimension à la notion de famille : elle ne se réduit pas aux liens du sang, mais s'étend à l'affection que l'on porte sur son entourage, qu'ils soient parents, proches, domestiques, voisins, collègues. On retrouve toutefois les sentiments d'amour familial au XVIII ${ }^{\mathrm{e}}$ siècle, chez Le Prince d'Ardenay : "Mon père et ma mère célébraient, chaque année, avec leurs enfants, l'anniversaire de leur mariage ${ }^{158}$ ", raconte-t-il; ses parents sont pour lui " deux personnages chéris ". Fleury est très attaché à son père : "Au milieu de tous mes chagrins, j'éprouvoi une grande consolation dans l'arrivée de mon père qui passa un an avec moi ${ }^{159}$ ", raconte-t-il.

Jusqu'au XVII ${ }^{\mathrm{e}}$ siècle, dans le mariage, l'amour entre les deux conjoints se caractérise par la " parfaite amitié ${ }^{160}$ " et l'estime qui les unit. Les termes " inclination " et " affection " s'utilisent indistinctement pour l'amitié ou pour le mariage; le terme d'amour n'apparaît pas dans les minutes notariales ${ }^{161}$. Les parents de Julien II Bodreau " ont veuscu en parfaicte union et amitié conjugale trente et huict ans huict mois ${ }^{162}$ ", de 1598 à 1636, et le décès de son père va selon lui "relaisser en viduitté "sa mère jusqu'à sa mort, en 1642. La passion, qui est l'amour "furieux ", est réservée pour le sentiment amoureux ${ }^{163}$ - hors mariage? -. On peut aimer d'amitié, aimer pour le mariage, mais la noblesse laisse au couple bourgeois l'amour conjugal, inavouable, " par la crainte de vous déplaire ou de perdre quelque chose de votre estime ", avoue dans le roman le prince de Clèves agonisant à sa femme ${ }^{164}$. L'amour est une faiblesse, mais le goût des deux époux est

157. MourssET, Sylvie, "De père en fils : livre de raison et transmission de la mémoire familiale (France du Sud, XV ${ }^{\mathrm{e}}$-XVIII ${ }^{\mathrm{e}}$ siècle) ", p. 139-151, in : Religion et politique dans les sociétés du Midi, Paris, Éditions du CTHS, 2002.

158. Pour cette citation et la suivante : Esnault, Gustave-René, Mémoires de J.-B.-H.-M. Le Prince..., op. cit., p. 43.

159. FleUry, Jacques-Pierre, Mémoires sur la Révolution ..., op. cit., p. 132.

160. Ranum, Orest, "Les refuges de l'intimité ", p. 209-259, dans ARIÈs, Philippe et DuBY, Georges (dir.), Histoire de la vie privée, op. cit., p. 249.

161. Fillon, Anne, Les Trois bagues..., op. cit., p. 127.

162. Pour cette citation et la suivante : Livre de raison de la famille Bodreau, $\mathrm{f}^{\circ} 113 \mathrm{v}^{\circ}$.

163. Bologne, Jean Claude, Histoire du sentiment amoureux, Paris, Flammarion, 1998, p. 74 .

164. La Fayette, Marie-Madeleine Pioche de La Vergne, comtesse de, La Princesse de Clèves, Paris, Le Livre de poche, 1995 (rééd.). 
nécessaire à l'union, c'est pourquoi le mariage est précédé d'une période de fréquentation, de cour, où les futurs échangent lettres et cadeaux devant témoins. En 1657, Julien II Bodreau assiste au mariage de sa fille Marguerite avec Pierre Bourgault, il précise que la cérémonie a lieu " apres une perseverance de deux ans et plus ${ }^{165}$ ». De même, Pierre-Henri de Ghaisne raconte à propos de sa femme : " Je luy ay fait l'amour dix ans, après quoy mon père et ma mère ont bien voulu y consentir ${ }^{166}$ ", ils se marient en 1708 . C'est un mariage tardif pour lui : Ghaisne a 37 ans, sa femme en a 27. Le mariage est l'accomplissement de ces années de fréquentation : "Ce fut le 12 janvier 1764 qu'elle prononça ce premier oui, jour heureux et bien mémorable pour moi, puisque c'est de ce jour que part l'ère fortunée de ma félicité ${ }^{167}$ ", raconte Le Prince d'Ardenay. «L'amour peut aller au-delà du tombeau, mais elle ne va guère au-delà du mariage 168 "; ces vers n'ont plus cours dans les milieux aisés de province au XVIII ${ }^{\mathrm{e}}$ siècle. Consultons pour cela les mémoires de Louis Simon, qui ont pour principal sujet les mésaventures du jeune étaminier avant d'enfin épouser Anne Chapeau, avec qui il vit en parfaite entente toute sa vie. En effet, il convient désormais d'interroger ses sentiments lors de la recherche d'un parti : "Quand le cour n'est pas de la partie, il faut la quitter ${ }^{169}$ ", affirme Jean-Baptiste Le Prince d'Ardenay. "La passion est nécessaire pour s'épouser ", assure de son côté Nicolas Rétif de la Bretonne ${ }^{170}$. La femme de Stanislas Dupont de la Motte arrive incognito à La Flèche : "Malgré les caresses, je ne me laissai aller à aucune faiblesse ${ }^{171}$ ", écrit le diariste, mécontent de cette arrivée inopportune. À la lecture de cette phrase, le couple marital devient cependant le refuge de la tendresse.

On ne trouve dans les écrits du for privé que peu d'informations sur l'épouse si ce n'est au moment de sa mort, qui est l'occasion de la louer. À la fin du Xvie siècle, un des auteurs du livre de raison des Le Vayer appelle avec fierté son épouse "nostre damoiselle ${ }^{172}$ ". Selon Louis Simon, sa femme a " des grâces et des attraits qui charmaient les cœurs ${ }^{173}$ ", et pour Le Prince d'Ardenay, elle est " celle qui était destinée par la Providence à faire [s] on bonheur ${ }^{174}$ ". L'emploi d'un vocabulaire affectif est rare, apprécions alors ce mot d'Ardenay, qui appelle sa femme " ma princesse ${ }^{175}$ ". Dans ses mémoires, il ne parle pas du tout de sa mort, le 27 avril 1805, mais

165. Livre de raison de la famille Bodreau, $\mathrm{f}^{\circ} 188 \mathrm{v}^{\circ}$.

166. Esnault, Gustave-René, Les livres de famille dans le Maine, tome 1 : Livre-journal de Pierre-Henri de Ghaisne de Classé, op. cit.

167. Esnault, Gustave-René, Mémoires de J.-B.-H.-M. Le Prince..., op. cit., p. 55.

168. M ${ }^{\mathrm{me}}$ DE SCUDÉRY, Le Grand Cyrus (1649).

169. Esnault, Gustave-René, Mémoires de J.-B.-H.-M. Le Prince..., op. cit., p. 46.

170. RÉTIF DE LA Bretonne, Nicolas, Le paysan perverti, 105e lettre, cité par Bologne, JeanClaude, Histoire du sentiment amoureux, op. cit., p. 107.

171. 4 janvier 1772, BoIsson, Didier, Le journal de Stanislas Dupont..., op. cit., p. 62.

172. BARET, René, Le Livre de raison de Michel Le Vayer, op. cit.

173. FILlon, Anne, Les Trois bagues aux doigts..., op. cit.

174. Esnault, Gustave-René Mémoires de J.-B.-H.-M. Le Prince..., op. cit., p. 46.

175. Ibidem, p. 182. 
elle l'influence fortement : “Après le malheur immense que j'ai éprouvé, je pus un peu réfléchir, je sentis vivement le besoin d'une forte distraction. [...] Je me déterminai à renoncer au commerce ${ }^{176}$. „ C'est René Desboys du Chastelet, au cours du XVII ${ }^{\mathrm{e}}$ siècle, qui exprime peut-être le mieux ce qu'est l'amour : « Il est vray que la personne aimée fait le Ciel ou le Paradis où elle est; \& je ne m'étonne plus qu'Orphée ait préféré la demeure des Enfers au séjour de la terre ${ }^{177}$."

On dit souvent que l'écrit intime à proprement parler, celui qui ne concerne que soi et met au jour sa conscience et sa subjectivité propre, n'apparaît que vers la toute fin du XVIII ${ }^{\mathrm{e}}$ siècle, voire au début du XIX ${ }^{\mathrm{e}}$ siècle. "Penser à soi " n'est pas "se penser, soi ${ }^{178}$ ": si le récit de la vie personnelle ne présente aucun intérêt, on a pu constater que pour ces élites provinciales de l'Ouest, le for privé et l'intimité deviennent tout de même, au cours de l'époque moderne, des sujets d'écriture plus développés. On copie ce qui vient d'en haut, c'est-à-dire du roi et de la noblesse. Une volonté d'intimité s'est peut-être d'abord développée par l'exemple de Louis XIV, qui se retire dans les appartements de madame de Maintenon et qui construit Marly dans la deuxième partie de son règne, pour un cercle choisi, plus restreint; puis suivant l'exemple de Louis XV et ses soupers privés, de Louis XVI et sa vie de famille, quasiment bourgeoise. Cela libère la noblesse, qui a plus de temps à consacrer à sa vie personnelle, mais pour les milieux plus modestes, désireux toutefois de copier les élites, les contraintes de la vie quotidienne limitent l'espace de l'intime dans les écrits du for privé.

Il est vrai que les faits divers, les comptes, les possessions et la famille restent, comme au Moyen Âge, les thèmes les plus fréquents des ego-documents d'Ancien Régime, mais apparaît peu à peu la notion d'individualité, et le moi commence à s'exposer. L'intime s'exprime-t-il au cours de cette période à travers le récit de la vie spirituelle, affective, à travers la vie du corps et la maladie, ou bien encore de la sexualité? Écrire sur soi reste une activité restreinte : tout ce qui relève de l'affectif et des sens est encore refoulé, il faut lire entre les lignes et deviner, supposer, sans jamais extrapoler. De plus il a déjà été montré que les mêmes qualités sont toujours mises en avant, "sincérité, aménité, crédibilité, prudence dans le jugement, puis charité chrétienne ${ }^{179} "$; et c'est majoritairement de façon indirecte, par le biais des tournures de phrase ou de la manière de raconter les divers événements d'une vie, que le moi privé et le for intérieur s'expriment réellement. L'histoire de l'intime est un sujet d'étude très mal connu des historiens, une de ses plus grandes difficultés étant la rareté des sources; "il

176. Ibid., p. 277.

177. Desboys du Chastelet, René, L'Odyssée, op. cit., p. 43.

178. Termes employée par ChaRBonNEAU, Frédéric, "Les mémoires français du XVII ${ }^{\mathrm{e}}$ siècle : Prolégomènes à l'établissement d'un corpus ", XVII Siècle, n ${ }^{\circ}$ 191, p. 349-357.

179. DENIs, Delphine, "Documents, texte, discours?", BARDET, Jean-Pierre et RugGiU, François-Joseph (dir.), Au plus près du secret des cœeurs?... op. cit., p. 63-72. 
faut le chercher ${ }^{180}$ ", conclut donc Orest Ranum, et l'ego-document apparaît pour cela comme une source certes ingrate mais toujours essentielle : " Le moi n'est pas un donné, c'est au creuset des expériences et des désirs, des joies et des douleurs, de la fièvre et des rêves qu'il se forge ${ }^{181}$ ", autant de thèmes abordés en filigrane dans les écrits du for privé.

\section{RÉSUMÉ}

Les écrits du for privé (livres de raison, mémoires, journaux intimes) ont de multiples utilités à l'époque moderne. Leurs auteurs s'en servent pour relater les faits divers locaux et les derniers événements, dont les hausses et baisses de prix ainsi que les incidents météorologiques. Ils sont aussi livre de comptes, souvenir de la mémoire familiale et chronique des naissances et décès survenus dans l'entourage de l'auteur. Au final, la part du privé au sens strict se révèle parfois inexistante. On constate toutefois une certaine évolution dans les pratiques de l'écrit intime chez les élites sociales et intellectuelles du Haut-Maine (actuelle Sarthe) au cours de l'époque moderne.

\section{ABSTRACT}

Private documents (accounts books, memoires, private diaries) are used in many ways during $16^{\text {th }}$ to $18^{\text {th }}$ Century. Authors record local facts, short news and last events, and amongst them, prices' reductions and increases as well as weather incidents. They also serve as accountancy support, family's memory, and birth and death chronicle in the author's circle. In the end, private events - stricto sensu - are not very present in those writings. However, a certain evolution can be seen in the practice of private writing, in Haut-Maine (current departement of Sarthe) social and intellectual elite, along modern time.

180. RANUm, Orest, «Les refuges de l'intimité ", art. cit., p. 209.

181. HiPP, Marie-Thérèse, Mythes et réalités. Enquête sur le roman et les mémoires (16601700), Paris, Klincksieck, 1976, p. 262. 